\title{
SISTEM PENGUPAHAN TENAGA KERJA PADA USAHATANI PADI DI KECAMATAN BRANG REA KABUPATEN SUMBAWA BARAT
}

\section{LABOR WAGE SYSTEM ON RICE FARMING IN THE BRANG REA SUB DISTRICT WEST SUMBAWA REGENCY}

\author{
Pristi Anugrah Putri, Anwar, IGL. Parta Tanaya \\ Faklultas Pertanian Universitas Mataram
}

\begin{abstract}
ABSTRAK
Tujuan penelitian ini adalah untuk Mengidentifikasi penggunaan tenaga kerja pada usahatani padi di Kecamatan Brang Rea kabupaten Sumbawa Barat, Untuk mengetahui penetapan besaran upah dan sistem pengupahan tenaga kerja pada usahatani padi di Kecamatan Brang Rea Kabupaten Sumbawa Barat, Mengetahui Kendala yang dihadapi petani dalam usahatani padi di Kecamatan Brang Rea Kabupaten Sumbawa Barat. Metode penelitian yang digunakan adalah menggunakan metode Deskriptif. sebanyak 30 responden, 12 petani dari Desa Tepas dan 18 petani dari Desa Tepas Sepakat. Masing-masing ditentukan secara accidental sampling yaitu tekhnik penentuan sampel berdasarkan kebetulan, yaitu responden yang secara kebetulan atau incidental bertemu dengan peneliti dapat digunakan sebagai sumber data. Hasil penelitian menunjukkan : 1) Penggunaan rata-rata tenaga kerja sebanyak 34,93 HKO/LLG dengan upah Rp 2.576.756/LLG. Rata-rata biaya atau upah per aktivitas terbesar yang dikeluarkan pada usahatani padi di Kecamatan Brang Rea Kabupaten Sumbawa Barat yaitu pada kegiatan panen sebesar Rp 1.080.000/LLG. 2). Sistem pengupahan di Kecamatan Brang Rea Kabupaten Sumbawa Barat yaitu sistem upah harian dan borongan. Upah borongan hanya digunakan pada kegiatan pembajakan sawah sebesar Rp 642.000 per LLG, sedangkan upah harian digunakan pada saat kegiatan penanaman, penyiangan, pemupukan, penyemperotan sebesar Rp 50.000 per LLG, dan pada kegiatan panen menggunakan upah bagi hasil dengan rata-rata produksi padi yang dikeluarkan petani 3 karung atau sama dengan $225 \mathrm{~kg}$ gabah dengan upah sebesar Rp 1.080.000 per LLG.
\end{abstract}

Kata kunci : Tenaga Kerja dan Sistem Pengupahan.

\section{ABSTRACT}

The purpose of this study was to identify labor use in rice farming in Brang Rea Sub-district, West Sumbawa Regency, to determine wage setting and labor wage systems in rice farming in Brang Rea SubDistrict, West Sumbawa Regency, to find out the constraints faced by farmers in farming rice in Brang Rea District, West Sumbawa Regency. The research method used is descriptive method. 30 respondents, 12 farmers from Tepas Village and 18 farmers from Tepas Sepakat Village. Each is determined by accidental sampling, which is a sampling technique based on chance, that is, respondents who incidentally or incidentally meet with researchers can be used as data sources. The results of the study show: 1) The use of an average workforce of $34.93 \mathrm{HKO} / \mathrm{LLG}$ with a wage of Rp. 2,576,756 / LLG. The average cost or the biggest wage per activity spent on rice farming in Brang Rea Subdistrict, West Sumbawa Regency is in the harvesting activity of Rp. 1,080,000 / LLG. 2). The wage system in the District of Brang Rea, West Sumbawa Regency is a system of daily wages and bulk. The piece rate is only used for rice field piracy activities in the amount of Rp. 642,000 per LLG, while daily wages are used when planting, weeding, fertilizing, desludging activities of Rp. 50,000 per LLG, and in harvesting activities using profit-sharing wages with the average rice production farmers of 3 sacks or equal to $225 \mathrm{~kg}$ of grain with wages of Rp. 1,080,000 per LLG.

Keywords: Labor and Wage System.

Putri, P. A., Anwar, dan Tanaya I.G.L.P. 


\section{PENDAHULUAN}

Kebutuhan bahan pangan utama khususnya beras semakin meningkat sesuai dengan laju pertumbuhan penduduk dan perkembangan kondisi perekonomian masyarakat. Penerapan teknologi pertanian seperti penggunaan benih unggul bermutu dan penggunaan pupuk yang berimbang dan juga telah banyak membantu meningkatkan hasil pertanian. Namun di sisi lain oganisasi petani (kelompok tani) sebagian besar nampak kurang mampu untuk menghimpun dana/ modal untuk dapat memenuhi kebutuhannya dalam berusaha tani, khususnya dalam penyediaan sarana produksi yang tepat jumlah dan tepat waktu. Salah satu subsektor pertanian yang memiliki kontribusi cukup besar adalah tanaman pangan terutama komoditi padi. Peran strategis subsektor tanaman pangan yang utama adalah dalam hal penyediaan pangan bagi masyarakat dan penyerapan tenaga kerja. (Dwi Wahyuni, 2016)

Masyarakat petani di perdesaan pada umumnya masih tergolong miskin dan mayoritasnya mengandalkan tenaga kerja sebagai sumber daya utama dalam proses produksi. Buruh tani sebagai salah satu komponen pada sektor pertanian, mempunyai kontribusi yang cukup besar dalam menentukan keberhasilan sektor ini. Kenyataan dilapangan menunjukkan bahwa keberhasilan sektor ini tidak selalu diikuti oleh meningkatnya kesejahteraan buruh tani. Hal tersebut disebabkan masih rendahnya upah buruh tani di Indonesia, sementara disisi lain harga barang-barang untuk memenuhi kebutuhan hidup sehari-hari terus meningkat. Perkembangan tingkat upah sektor pertanian pun tidak berjalan searah dengan kenaikan harga kebutuhan pokok sehingga berimpliksi negatif terhadap daya beli dan kesejahteraan buruh tani. Rendahnya pendapatan buruh tani juga tidak terlepas dari rendahnya partisipasi dan akses buruh tani terhadap kesempatan kerja diluar sektor pertanian. Buruh tani sebagai salah satu komponen pada sektor pertanian, mempunyai kontribusi yang cukup besar dalam menentukan keberhasilan sektor ini. Namun pada kenyataanya, keberhasilan sektor ini tidak selalu diikuti oleh meningkatnya kesejahteraan buruh pertanian terutama dalam situasi perekonomian Indonesia saat ini. Hal tersebut disebabkan masih rendahnya upah buruh tani di Indonesia, sementara di sisi lain harga barang-barang untuk memenuhi kebutuhan hidup sehari-hari terus meningkat. (Jurnal bisnis, 2016)

Ada beberapa sistem pengupahan dalam hubungan kerja pada masyarakat pertanian yaitu sistem bawon, upah harian, upah borongan, upah bulanan atau mingguan, dan lainnya. Semua sistem pengupahan ini merupakan bentuk pertukaran antara tenaga dan materi dalam hubungan kerja. Besarnya jumlah upah yang diperoleh oleh buruh tani ditetapkan berdasarkan kesepakatan masyarakat yang ada di desa tersebut. Besarnya jumlah upah yang ditetapkan atau yang diberikan oleh petani kepada hubungan tani juga dipengaruhi oleh relasi sosial yang terjalin. Bahkan dalam sistem pengupahan terdapat perbedaan upah berdasarkan jenis kelamin.

Usaha tani padi sawah di Kecamatan Brang Rea Kabupaten Sumbawa Barat belum diketahui bagaimana sistem pengupahan terhadap tenaga kerja, apakah jumlah produksi yang dihasilkan sudah memberikan keuntungan yang maksimal. Hal ini disebabkan tidak diketahui apakah penggunaan faktor produksi dalam usaha tani padi sawah sudah efisien atau belum efisien. Faktor produksi yang berpengaruh pada usahatani padi sawah adalah luas lahan, benih, pupuk, dan tenaga kerja.

Berdasarkan uraian diatas, maka yang menjadi inti permasalahan adalah bagaiamana sistem upah yang digunakan pada usahatani padi, oleh karena itu perlu dilakukan penelitian dengan judul "Sistem Pengupahan Tenaga Kerja Padi di Kecamatan Brang Rea Kabupaten Sumbawa Barat”.

\section{METODOLOGI PENELITIAN}

Penelitian ini menggunakan metode Deskriptif, yaitu metode yang tertuju pada pemecahan masalah yang ada pada waktu sekarang dengan cara mengumpulkan data kemudian menyusun dan menginterpretasikan data, menetapkan hubungan dan kebutuhan masing-masing variabel yang di teliti dan selanjutnya dianalisa dan menarik kesimpulan (Nasir, 1988). Pengumpulan data dilakukan dengan mewawancarai responden dengan berpedoman pada daftar pertanyaan yang telah di persiapkan. (Surakhimad,

1990). Unit analisis dalam penelitian ini adalah petani/buruh tani yang melakukan usahatani padi. Penentuan Daerah Penelitian, Penelitian ini dilakukan di Kecamatan Brang Rea Kabupaten Sumbawa Barat. Dari sembilan desa yang ada di Kecamatan Brang Rea, ditetapkan dua desa sebagai lokasi penelitian secara purposive sampling dengan memilih Desa Tepas dan Tepas Sepakat sebagai lokasi penelitian, dengan pertimbangan lokasi merupakan daerah yang banyak menghasilkan komoditi padi. Penentuan Sampel, Penentuan jumlah petani responden pada tiap desa terpilih ditentukan secara proporsional sampling yaitu responden sebagai sampel ditetapkan secara quota sampling sebanyak 30 responden, 12 petani dari Desa Tepas dan 18 petani dari Desa Tepas Sepakat. Masing-masing ditentukan secara accidental sampling yaitu tekhnik penentuan sampel berdasarkan kebetulan, yaitu responden yang secara kebetulan atau incidental bertemu dengan peneliti dapat digunakan sebagai sumber data. 


\section{HASIL DAN PEMBAHASAN}

\section{Umur Responden}

Menurut Simanjutak dalam Kinati (2015), umur mempunyai pengaruh terhadap fisik petani dalam mengelolah usahataninya. Semakin tua umur umur petani responden, maka kemampuan kerjanya relative menurun. Rata- rata umur responden kisaran 32-56 tahun. Ini menunjukkan umur responden mampu bekerja dengan secara fisik maupun mental untuk menghasilkan barang dan jasa. Umur dapat mempengaruhi fisik dalam bekerja, cara berfikir, serta keinginan untuk menerima ide-ide baru dalam mengelola usaha taninya. Kisaran umur responden 15 - 64 tahun sebanyak 30 orang responden dengan persentase $100 \%$. Perincian Tabel 1.

Tabel 1 Sebaran Umur Responden Pada Usahatani Padi di Kecamatan Brang Rea

\begin{tabular}{|l|c|c|c|}
\hline No. & Kisaran Umur & Jumlah (orang) & Persentase (\%) \\
\hline 1. & $20-56$ & 26 & 92,00 \\
2. & $>56$ & 4 & 8,00 \\
\hline \multicolumn{2}{|c|}{ Jumlah } & 30 & 100 \\
\hline
\end{tabular}

Sumber : Data Primer Diolah, (2018)

Tabel 1 menunjukkan bahwa umur responden berada pada kisaran umur 20-50 tahun hal ini menunjukkan bahwa responden termasuk dalam kelompok usia produktif.

\section{Tingkat Pendidikan Responden}

Pendidikan merupakan aspek yang penting dalam mengembangkan Sumber Daya Manusia (SDM). Pendidikan dapat meningkatkan kualitas dan produktivitas tenaga kerja. Tingkat pendidikan seseorang akan berpengaruh dalam cara berpikir dan kesiapan untuk menerima suatu inovasi. Untuk lebih jelasnya dapat dilihat pada tabel 2 .

Tabel 2. Sebaran Usahatani Padi Berdasarkan Tingkat Pendidikan pada Usahatani Padi di Kecamatan Brang Rea Tahun 2018

\begin{tabular}{|l|l|c|c|}
\hline No. & \multicolumn{1}{|c|}{ Tingkat Pendidikan } & $\begin{array}{c}\text { Jumlah } \\
\text { (Orang) }\end{array}$ & $\begin{array}{c}\text { Persentase } \\
(\%)\end{array}$ \\
\hline 1. & Tidak Sekolah & 4 & 12 \\
2. & Tamat SD (Sekolah Dasar) & 13 & 51 \\
3. & Tidak Tamat SD (Sekolah Dasar) & 2 & 6 \\
4. & Tamat SMP (Sekolah Menengah Pertama) Tamat SMA & 5 & 15 \\
5. & (Sekolah Menengah Atas) & 5 & 15 \\
\hline Jumlah & 30 & 100 \\
\hline
\end{tabular}

Sumber : Data Primier Diolah, (2018)

Dari Tabel 2 menunjukkan petani padi yang tamat Sekolah Dasar (TSD) sebanyak 13 orang (51\%).

\section{Jumlah Tanggungan Keluarga}

Anggota keluarga terdiri dari ibu, anak dan orang lain yang tinggal dalam keluarga tersebut. Jumlah anggota keluarga akan berpengaruh terhadap biaya hidup dan ketersediaan tenaga kerja dalam keluarga. Semakin banyak anggota keluarga maka semakin besar pula biaya hidup yang dikeluarkan. Karakteristi jumlah tanggungan keluarga dapat dilihat pada tabel berikut. 
Tabel 3. Jumlah Tanggungan Keluarga Petani Responden pada Usahatani Padi di Kecamatan Brang Rea Tahun 2018

\begin{tabular}{|l|c|c|c|}
\hline No. & $\begin{array}{c}\text { Kisaran Jumlah Tanggungan } \\
\text { Keluarga }\end{array}$ & $\begin{array}{c}\text { Jumlah } \\
\text { (orang) }\end{array}$ & $\begin{array}{c}\text { Persentase } \\
(\%)\end{array}$ \\
\hline 1. & $1-2$ & 7 & 23,33 \\
2. & $3-4$ & 10 & 33,33 \\
3. & $\geq 5$ & 13 & 43,34 \\
\hline \multicolumn{2}{|l|}{ Jumlah } & 30 & 100,00 \\
\hline
\end{tabular}

Sumber : Data Primer Diolah, (2018)

Tabel 3 menunujukkan bahwa kisaran anggota keluarga responden yang terbesar yaitu pada jumlah tanggungan keluarga responden petani padi memiliki yang tertinggi berada pada kisaran 5 sebanyak 13 orang $(43,34 \%)$.

\section{Pengalaman Berusahatani Responden}

Pengalaman berusahatani sebagai responden berkaitan dengan faktor kebiasaan. Responden petani yang memiliki pengalaman berusahatani lebih lama akan mempengaruhi keputusan tepat demi mencapai hasil yang optimal. Untuk mengetahui rata-rata pengalaman usahatani padi petani responden dapat dilihat dalam Tabel 4.

Tabel 4. Sebaran Responden Berdasarkan Pengalaman Berusahatani Pada Usahatani Padi di Kecamatan Brang Rea Tahun 2018

\begin{tabular}{|c|c|c|c|}
\hline No. & $\begin{array}{l}\text { Lama Berusahatani } \\
\text { (Tahun) }\end{array}$ & Jumlah (orang) & Persentase $(\%)$ \\
\hline $\begin{array}{l}1 . \\
2 . \\
3\end{array}$ & $\begin{array}{c}4-10 \\
11-20 \\
21-40\end{array}$ & $\begin{array}{c}4 \\
6 \\
20\end{array}$ & $\begin{array}{l}13,33 \\
20,00 \\
66,67\end{array}$ \\
\hline \multicolumn{2}{|r|}{ Jumlah } & 30 & 100 \\
\hline
\end{tabular}

Sumber : Data Primer Diolah, (2018)

Tabel 4 menunjukkan bahwa kisaran pengalaman berusahatani responden pada usahatani padi tertinggi yaitu pada kisaran $21 \mathrm{~s} / \mathrm{d} 40$ tahun sebanyak 20 orang responden $(66,67 \%)$.

\section{Status Penguasaan Lahan Petani}

Luas lahan garapan merupakan salah satu faktor pendukung dalam menjalankan usahatani padi. Luas lahan petani menentukan tingkat ekonomi petani. Luas lahan garapan yang dimiliki petani responden usahatani padi dapat dilihat pada tabel berikut.

Tabel 5. Sebaran Luas Lahan Garapan Pada Usahatani Padi di Kecamatan Brang Rea Tahun 2018

\begin{tabular}{|c|c|c|c|}
\hline No. & Luas Lahan Garapan (ha) & Jumlah (orang) & Persentase $(\%)$ \\
\hline 1. & $\leq 0,50$ & 20 & 66,67 \\
\hline 2. & $>0,50$ & 10 & 33,33 \\
\hline \multicolumn{2}{|r|}{ Jumlah } & 30 & 100,00 \\
\hline
\end{tabular}

Sumber : Data Primer Diolah, (2018)

Tabel 5 menunjukkan status penguasaan lahan sangat mempengaruhi besarnya tingkat pendapatan tenaga kerja responden dalam mengambil keputusan tentang usahataninya. Responden yang memiliki luas lahan terbesar yaitu pada kisaran $\leq 0,50$ ha sebanyak 20 0rang dengan persentase $(66,67 \%)$. 


\section{Gambaran Umum Penggunaan Tenaga Kerja}

Penggunaan tenaga kerja dapa dilihat dari jenis-jenis pekerjaan yang ada pada usahatani padi yaitu mempersiapkan lahan, Membajak dan mencangkul, pemilihan bibit unggul, penyemaian benih, penanaman, pemupukan, penyiangan, dan pemanenan. Dari semua jenis pekerjaan yang ada pada usahatani padi ini tidak semuanya dilakukan tenaga kerja laki-laki melainkan ada perempuan yang ikut mengerjakannya. Berikut jenisjenis pekerjan yang dikerjakan oleh responden pada Tabel 1. berikut.

Tabel 6. Rata-Rata Penggunaan Tenaga Kerja pada Usahatani Padi Per LLG Pada Setiap Jenis Pekerjaan di Kecamatan Brang Rea Kabupaten Sumbawa Barat.

\begin{tabular}{|c|l|c|c|}
\hline \multirow{2}{*}{ NO } & \multicolumn{2}{|c|}{ Kegiatan } & \multicolumn{2}{|c|}{ LLG } \\
\cline { 3 - 4 } & \multicolumn{1}{|c|}{ Jumlah HKO } & Nilai (Rp) \\
\hline 1. & Pengolahan Lahan & 3.73 & 642.000 \\
2. & Penanaman & 6.03 & 298.333 \\
3. & Pemupukan & 2.37 & 103.090 \\
4. & Penyiangan & 6.80 & 353.333 \\
5. & Penyemperotan & 2.00 & 100.000 \\
6. & Panen & 14.00 & 1.080 .000 \\
\hline Jumlah & & 34.93 & 2.576 .756 \\
\hline
\end{tabular}

Sumber : Data primer Diolah (2018)

Tabel 6 menunjukkan bahwa rata-rata biaya atau upah per aktivitas terbesar yang dikeluarkan pada usahatani padi di kecamatan Brang rea Kabupaten Sumbawa Barat yaitu pada kegiatan panen sebesar Rp 1.080.000/LLG dengan penggunaan tenaga kerja sebesar 34,93 HKO/LLG.

Distribusi Buruh Tani Menurut Jenis Pekerjaan Pada Usahatani Padi di Kecamatan Brang Rea Kabupaten Sumbawa Barat Tahun 2018

Untuk mengetahui sejauh mana identifikasi pekerjaan buruh tani pada usaha tani padi, maka dilakukan pengukuran pada aspek terlibat dalam usahatani padi. Identifikasi buruh tani dapat dilihat pada Tabel 7.

Tabel 7. Distribusi Buruh Tani Menurut Jenis Pekerjaan Pada Usahatani Padi di Kecamatan Brang Rea Kabupaten Sumbawa Barat 2018

\begin{tabular}{|c|l|c|c|}
\hline \multirow{2}{*}{ No } & \multirow{2}{*}{ Jenis Kegiatan } & \multicolumn{2}{|c|}{ Jumlah Responden yang Mengikuti } \\
\cline { 3 - 4 } & & HKO & Persentase $(\%)$ \\
\hline 1. & Pengolahan Lahan & 3,73 & 10,68 \\
2. & Penanaman & 6,03 & 17,27 \\
3. & Pemupukan & 2,37 & 6,79 \\
4. & Penyiangan & 6,80 & 19,46 \\
5. & Penyemprotan & 2,00 & 5,72 \\
6. & Panen & 14,00 & 40,08 \\
\hline \multicolumn{2}{|c|}{ Total } & 34,93 & 100,00 \\
\hline
\end{tabular}

Sumber : Data Primier Diolah, (2018)

Tabel 7 menunjukkan HKO terbanyak 3,73 pada kegiatan pemanenan dengan persentase 40,08\%, ini dikarenakan proses pemanenan banyak menggunakan tenaga kerja, karena prosesnya yang begitu panjang dari mulai memotong padi hingga pada tahap begelondong dengan menggunakan bantuan mesin.

Penetapan Besaran dan Bentuk Upah Tenaga Kerja Pada Usahatani Padi di Kecamatan Brang Rea

Upah adalah pendapatan yang diterima tenaga kerja dalam bentuk uang. Sistem pengupahan merupakan suatu kebijakan dan strategi yang menentukan kompensasi yang diterima oleh seorang pekerja. Kompensasi ini merupakan bayaran atau upah yang diterima oleh pekerja sebagai balas jasa atas hasil kerja mereka. Penentuan upah dapat dilihat dari tabel 8. 
Tabel 8. Rata-Rata Penetapan Besaran dan Bentuk Upah Tenaga Kerja pada usahatani Padi di Kecamatan Brang Rea Kabupaten Sumbawa Barat Tahun 2018.

\begin{tabular}{|l|l|r|c|c|c|c|}
\hline \multirow{3}{*}{ No } & \multirow{3}{*}{ Jenis Pekerjaan } & \multicolumn{5}{|c|}{ Upah Tenaga Kerja } \\
\cline { 3 - 7 } & & \multicolumn{5}{|c|}{ Desa Tepas dan Desa Tepas Sepakat } \\
\cline { 3 - 7 } & & $\begin{array}{r}\text { Upah } \\
\text { (Rp) }\end{array}$ & $\begin{array}{r}\text { Rata2/ } \\
\text { LLg }\end{array}$ & $\begin{array}{c}\text { Hari } \\
\text { Kerja }\end{array}$ & HKO & Total Upah \\
\hline 1. & Pengolahan & 300.075 & 0,43 & 2 & 10.68 & 642.000 \\
2. & Lahan Penanaman & 50.000 & 0,43 & 2 & 17.27 & 298.333 \\
3. & Pemupukan & 65.000 & 0,43 & 2 & 6.79 & 145.000 \\
4. & Penyiangan & 50.000 & 0,43 & 3 & 19.46 & 353.333 \\
5. & Penyemperotan & 50.000 & 0,43 & 2 & 5.72 & 100.000 \\
6. & Panen & 1.080 .000 & 0,43 & 3 & 40.08 & 1.080 .000 \\
\hline
\end{tabular}

Sumber : Data Primer Diolah (2018).

Berdasarkan Tabel 8 upah terbesar dikeluarkan Pada kegiatan pemanenan menggunakan 14 tenaga kerja dengan upah sebesar $\mathrm{Rp} 1.080 .000$ selama tiga hari pengerjaan dengan rata-rata luas lahan garapan $0,43 \mathrm{Ha}$, pada kegiatan panen petani menggunakan sistem borongan untuk menyewa buruh tani sehingga total upah sebesar Rp 1.080.000. Proses penetapan upah yang mereka terima cash, upah yang diberikan pada buruh tani diberikan terlebih dahulu sebelum pekerjaan di mulai sehari atau sampai dua hari sebelum kegiatan berlangsung. Jika dilihat dari semua proses, pada proses panen lebih banyak membutuhkan tenaga kerja dan menghabiskan 3-4 hari kerja dengan rata-rata total upah sebesar Rp 1.080.000.

\section{KESIMPULAN DAN SARAN}

\section{Kesimpulan}

Berdasarkan hasil penelitian, pembahasan, dan analisis data yang terbatas pada ruang lingkup penelitian ini, maka dapat ditarik kesimpulan sebagai berikut :

1. Penggunaan rata-rata tenaga kerja sebanyak 34,93 HKO/LLG dengan upah Rp 2.576.756/LLG.

2. kegiatan panen menggunakan upah bagi hasil dengan rata-rata produksi padi yang dikeluarkan petani 3 karung atau sama dengan $225 \mathrm{~kg}$ gabah dengan upah sebesar Rp 1.080.000 per LLG.

Saran

1. Diharapkan petani harus lebih meningkatkan produktifitasnya agar bisa mengelola lahan pertanian sehingga lahan tersebut masih bisa dikembangkan sehingga produksi padi bisa ditingkatkan lagi dan akhirnya pendapatan juga bisa meningkat, sehingga petani mampu menyewa buruh tani tanpa meminjam modal dari luar.

2. Diharapkan pemerintah agar membantu memberikan pinjaman modal atau kredit lunak bagi petani, agar memudahkan petani dalam berusahatani, apalagi pekerjaan pokok masyarakat adalah bertani.

\section{DAFTAR PUSTAKA}

Badan Pusat Statistik Propinsi NTB, 2017. Kecamatan Brang Rea Dalam Angka.

Badan Pusat Statistik Propinsi NTB, 2017. Luas wilayah desa di Kecamatan Brang Rea menurut jenis lahan. Mataram.

Nazir M, 1988. Metode Penelitian. Ghalia indonesia, Jakarta. Surakhimad,Winarno, 1990. Pengantar Penelitian Ilmia : Dasar Metode dan Teknik. Transito, Bandung.

Soekartawi, 2002. Prinsip-Prinsip Dasar Manajemen Pemasaran Hasil Pertanian : Teori Dan Aplikasinya.

Soekartawi, 2002. Analisis Usahatani. Jakarta: Penerbit Universitas Indonesia (UI-Press).

Wahyuni, Dwi. 2016. Jurnal Analisis Sistem Pengupahan "Bawon" Pada Pertanian padi (Studi Kasus Pada petani di Desa Gambar Kecamatan Wonodadi Kabupaten Blitar). Jurnal Bisnis Manajemen \& Perbankan Vol. 2 No. 22016 : 121-140. p-ISSN : 2338-4409. e-ISSN : 2528-4649 